\title{
Carta aos "dottores"
}

\author{
Pierina Cechini
}

\begin{abstract}
Senhores Dottores, Eu escrevi esta carta para esplicar todo ho que tenho pasado neste triste mundo.

Eu até a idade de 24 annos pacei um vida regular trabalhando dia e noite para poder viver, de dia narosa de noite, trabalhava de transa para chapeos assim, pasava.

Meu pai era zelador da estrada ganhava 30,000 por mês, eu so a urtima filha, elles conchetiu que me cazase in casa para, eu cuidar da sua velhice, e assim contece-u, me casei, quando me casei meu, pai, tinha, quatro sento mil mas não foi ganados na rosa, foi ganhados, na estrada, a rocha não dava praviver.

Assim se protemos para casar, o noivo muito pobre, elle não tinha ne pai ne mãi nem parentes, elle, estava em casa, dum profesor demusica, que vierão juntos, no, Brazil, elle quando tinha trabalho ia trabalhar fora, e quando não tinha ficava in casa mas elle pagava, um mil resis por dia de comida, a sustansa delle era um cavallo, ins silhado, elle dise, eu não poso, fazer nada porque não tenho dinhero, Eu lhe respondi para me casar
\end{abstract}

1. HOSPíCIO SÃo PEDRO. Prontuário n. 38120 - P. C. (Arquivo Público do Rio Grande do Sul-Cx. 06).

A transcrição da carta manteve fidelidade ao texto original na ortografia, sintaxe e pontuação. 
sem fazer um poço de festa isto não, consinto, assim, os meus, pais dicerão friceremos uma festa naquelle dia no hotel, eu pagerei a dispesa, elle me comprou o vestido e esta aliansa, que tenho o dedo, elle ficou devendo 45,000 , do vestido ao arfaiate, 20,000 ao carpentero da cama, 20,000, da despesa na casa donde elle morava, esse casemos vai fazer 4, annos agorar no dia 5 de Agosto, mas casemos so na Egreja, não casemos no sevil por farta de dinheiros, Eu me casei com essa idade mas não sabia hoque queria dicer marido foi sempre uma moça respetada de todos, e muito católica, eu me casei com esta a tenson de compagar, o meu marido ate ho dia da minha morte mas Deus, não quis e nimguem de comtentes neste mundo, o prauma cousa ou pra outra todos temos as nosas afflições, eu pençava de ter uma vida muito feliz, in veis, sou amais in felizes de todos os meus irmães, Agora vou lhe contar o prensipio da minha vida despois de casada.

O meu marido, principio trabalhar narosa, elle fiz os trabalhos mais necesarios depois, foi trabalhar, fora para puder, pagar as dividas que elle tinha, elle trabalho, dois mês, quando veio para casa pagou as suas dividas.

Quando elle veio ficou in casa um méis, trabalhando narosa, dpois foi travei, na estrada de fero, quando veio veio com 80,000 reis, intregou todo pra meu, pai, meu pai, queria assim, quando ia fora, dar todo o dinheiro pra elle, quando estava em casa trabalhar narosa e eu também o poço que ganhava entregar para elle, mais depois para tirar um vintém das mão delle, ou pedir, para comprar alguma cousa era presizo chorar, elle respondia que elle tinha de comprar a comida.

O meu marido tinha o visio de pitar, elle era, Soco da Sosiedade Italhiana de Moito Socoro, esta sosiedade paga um milreis pormeis, elle tinha o cavallo, que cada um méis, aveis precisava mandar ferar, e também quando elle era in casa, o sábado, ia fazer um pouco de festa ia cortar a barba, vinha bebedos as 11 ou ameia noite com todo, estas despeza que elle tinha o meu pai dava so um mil reis, no domingo, as sim elle em, estes quatros annos não comprou, nada pra nois vestit, eu coazi tenho acabado com os meus vestidos. Quando tive aminha filha, o meu marido tinha vinte mil reis escondidos, que o meu pai não, sabia, os senhores sabe que presisa de dinhero, quando fomos Batisar a menina, elle deu, um mereis como dava nos outros domingos, Mas Deus nos as [sic] judou, que o Padrinho, pagou toda a dispeza, Mas o meu marido se incomodou muito e medise, quando vou trabalhar, traveis, não dou, mais, nem um reis prateu pai intão isto foi, um prencipio, pra mim, os poucos dias, elle foi trabalhar, trabalhou dois, outreis, méis, o meu pai principiou, viu que demorava intregar os dinhero, todas as vezes, que ia com prar algumas cousas dizia sempre gastando e não ganhar nada isto não se pode, viver, foi in mais dois outrei mezes, ou meu, marido vendeu o cavallo, por sem mil reis, e tinha outros sem que tinha ganhado em 
este tempo que trabalho, e também meu pai creio que tinha um trezendo mil reis ou mais.

Quando, foi in prencipio Agosto, um dia de segunda feira, estava lavando o lenso de seda do meu marido tudo rasgado, a camisa também rasgada, as carsas, a mesma cousa, e a outra ropa da menina a minha e de todo a familha não prestava, pra nada, Itão me veio este pençamento, não temos nada pra vestir e nada pra comer, somos todo treis sem ropa, estes dozentos mil reis que temos, comprando, todo o que nos farta nāo sega nois temos de morer de fome, por que semos muito pobre, com este pensamento foi indo ate o Sábado, no Sábado contei pra minha mãe, eu dise pra ella mamãe, eu so loga, eu não tenho mais juízo nois temos de morer todos de fome não temos mais nada de comer nem de vistir, somos todos nus.

Quando, foi no domingo ja todo o povo sabia que, eu era loga, veio uma minha irmão, me disse, de tirar, a menina, de dar pra alguma familha que isto, podia ser, por causa que dava de mamar, pra menina e de não dar mais leite, proque, ella era muito, forte, pra ver, se era procausa da menina tirarão a pequena, na Segunda feira. Forão chamar o Dotor não me as sou duensa, neuma, me deu remédio, eu não queria tomar chorava, eu não quero que gastais, dinheiro, eu quero morer porque somos muito pobres, e vosei vão, gastar dinheiro prami, esta veis, foi 12,000 reis.

Eu sempre com esta hideia de querer morer de fome algum dias comia dois, ou treis não, comia a filhinha, ficou, lá 15 dias, depois, foi, boscar, ainda não tinha esta vontade, de affogar, pacei todo, Agosto, e Setembro, assim quando foi en prencipio, Outubro, na Sesta feira foi na cozinha garei uma vazihia botei, um, pouco, d agua, e botei o rosto dentro, quando, vi que não, podia mais ficar, tirei, fiz isto porque naquella noite queria, ir me affogar mas fiquei come dedo, não foi, hintão, naquella, noite, pencei doutra, maneira a manhã, chedo, me alevanto, e vou, mesconder, na capoeira, e fico, lá até morrer, isto fiz me allevantei, desei, todos, elles dormindo, e foi perto de casa tem, pedaço de capoeira, seguei lá me sentei, a minha mãe, perguntou ao meu marido, donde eu estava, elle dise, que elle estava, dormindo, não me viu, quando, me lavantei, ella pegou chorar e gritar, quem sabe la aonde ella está, agora, com a menina no colo, chorando, as duas, eu fiquei, com pena, foi, pra casa.

No fim de Outubro, meu marido, estava trabalhando na estrada de ferro, eu dise pra meu pãe que elle foçe dizer, propadrinho, que viesse boscar, a menina, senão, eu affogo, o meu pai me dise, proque tu que e affoga, tua filha e depois, eu me fecho, no me cuarto, semcomer, até morer. O meu, pai, foi, e mandou, chamar o meu marido, intão eu dice pra elle se, tu não da a menina, pra alguma familhia, eu affogo, e me tirou travei e botou, na mes casa, no mesmo, dia, e, que me tirão a menina eu foi na cama, e não, queria mais, que intra, se, ninguem, 
proque, eu queria morer, fiquei 22 sem comer nem ber agua, em estes 22, dias, meu pai mandou, Telegrama, aqui no, hospicio, veio, a resposta, que tinha, lugar.

Antes de sair, forão siamar, uma, mulher fiticera praver, se tinha algum fetiso, masa mulher, disse, que não tinha nada, se prontemos prais, diserão que pricisava um, atestado, do dellegado, o meu marido foi, na villa o meu conhado ferero, dise pra o meu marido, eu não quero, que a minha conhada vai no hospicio, ella não é loca, ella efraque-sa, que ella tem, leva ella na S. Casa intão, $\mathrm{O}$ intendente fiz a carta pra S. Casa. O meu marido, escuitou ao conselho do meu conhado mas meu pai ficou-u muito brabo, vimos eu meu marido e meu compadre, padrinho da meu anzinho, meu pai lhe deu 60,000 rs, esta viagia, nos costou mais de sem mil rs. Seguemos, em Portoalegre, fomos, no, hotel da Maria Teresa, O marido, della, e um conhe-sido noso, elle e de villa Garibaldi. O meu marido lhe contou, o fatto, que eu, tinha, esta vontade de, me mata e de morer, de fome, e de affogar, a menina, elle disse que na Santa Casa, não, merecebia so no hospicio, mas elle dise, que no hospicio precisava pagar 1 mil reis por dia, intão, ho meu, marido, eu não poso, pagar ummil reis por dia proque so muito, pobre, tenho, de pagar, $10 \mathrm{mil}$ reis, por meis pra pequena, eu não poso com todas estas despezas.

Eu não, queria, mais, ir pra casa, elle me dise eu na te boto no Ospicio pro que os parentes, não, quie e tão bem pra que não posso pagar, eu, dise pra casa eu tenho vergonha de ir, se tu quie ficar aqui na Rua, tu pode ficar em outro lugar eu não te boto, isto, aconteseu, no dia 13 de Novembro, eu dormi no hotel da Maria Teresa.

Seguemos na villa de noite, quando ho povo, soube que, que eu tinha voltado diserão que estes, dois homens, vo seis sois dois burros, forão Porto Alegre, paciar im veis de deixa a mulher no hospicio voltarão com ella. Voseis sois dois homens de palha. Eu estava, magra, que parecia um fantagema segue-i incasa foi na cama traveis e estava mais, in vergonhada, ainda, pegue a não comer, ainda fiquei um outro mês ainda depois um dia fierão as freira por forsa, me fizerão comer, ellas continu arranão, até no fim de fevereiro neste tempo que ellas vierão me cortarão os cabellos, porque me derão um banho, estava magra que parecia que uma hora pra outra tivese de morer. Neste tempo que vinha, as freras, destratava Deus, porque me creou e nossa Senhora não posso escrever todo senão presizaria, um jornal, eu chorava de vergonha de ser infeliz nomundo, me tirarão sangue, eu puzei, mais sangue, que cuazi era morte shego u minha irmã, eviu o cuarto todo sujo de sangue ella se assuto-u e me mararão as mãos; a minha sente me comprava socollate, vinho branco, todo, ache agente, dizia de fazer elles faziam, provarão outro dois fitiseros elles, tão bem diserão que não sou fitisada, o marido me dizia tu com a tua tristes hideias, tu me, assassinaste, me, etão bem a tua filha, em todo este tempo, eu dormia, com, o marido, mas, 
elle não foi mais, capaz de segar perto de mim praque, eu não queria se elle me dizia algma cousa, eu lhe respondia e chorava, por favor, no temos uma, menina, fora de casa, eu não quero, mais, que acontece outras desgraças vinha, muitas, coriosas me vizitar quando, estava na cama ellas me diziam, tenho, tanta pena da tua filha, de vella nas mãos, da tua vizinha pobre menina, in feliz para, sempre, de ter amãe loca, ellas, pesava que eu não, in tendia, no fim de Fevereio, me alevantei, e dise pra o marido, eu sha tenho isprementado, de tudo, para morer, não posso, morrer, até odia que Deus, marco u, E me-ior que tu vai buscar, a menina que eu não the faço, mais, nada, elle foi contentente, quando, eu mandei, buscar, afilha não, tinha, o desejoso, de matala, mas, eu rehorava, e destratava Deus porque elle fazia, morer, gente derepente, eu que estou com vergonha deser no mundo não me fais tu morer, tudo oque, eu dizia ella também dizia o marido, ficava brabo como, migo, elle medizia tu foste na escola das freiras para apprender adestratar Deus. No dia 17 de abril, faleceu, meu paie, na quelle dia, viera, muita mulheres, disserão, perto de mi pobre veio, podese diser que este homem moreu por causa de filha, elle se appaxono-u, com esta pois-cão elle moreu, eu fiquei invergonhada, Isto eu não nego isto pode acontecer, mais infim não costei, muito, eu quando, priensipi eta ideia, o meu pai tinha tresto, ou mais mil rs. quando elle falezeu assemos $40 \mathrm{mil}$, eu com o marido não podia mais iom binar pellas, lucuras, que tenho feito, elle sempre em dizia, tunão tinha outra para inganar tume ganaste, eu mas antes de me acontecer isto, elle erra muito contente de mim, e Na quinta feira antes de come ter ocrimi, assendi uma vella, e rezei muito, e quando accabei eu derezar me veio, este, pensa mento se elles vão a missa que, fique im casa sózinha, esta veis, affogo a Etelvina, eu não paso, viver, aqui, depois, o que vou, ono ospicio, ou na cadeia paracempre, e isto me acontece-u, eu, morava, na estrada geral passava grianças, olhiava prami, e disian, olha, alloca, eu pencei assim, a pobre filha, eu tenho este feio nome, de loca ella quando crescer, agente dizem, tu esloca como a tua mãe, eu estou muito arrependida, que quando, penso do meu anzinho, que eu poderia se incasa, com ella, in veis, estou, aqui, no meio de gente que não se quinha, mas ella no dia de oge creio que ela e muito mais feliz de que, eu, istonão foi feito por minha vontade porque eu pelo pasado não tinha coragem de matar nem uma galinha, cada pesoa lhe da a sua sorte, de pramim me deu uma sorte de cachorros, ou mais pior ainda, eu penso que diabo botou, os sivne minha familha, e escangaio-u, a familha, intera, elle queria tomar aminha, alma, elle me fizudiar, o meu corpo elle me fez duvidar, da lei de Deus, de pois, que esta, o meu anzinho ceu, não, escutei mais os, concelhos do diabo, seja feita avontade de Deus as naterra como no céu.

Eu quando, o Senhor, Juiz, me intero gou, lhe disse, ma tei a minha filha por cher muito pobre, para que elle nào foze padir esmola, e para medar pouco co-m o marido, e pra ella não me conheser como loca, Quando, estava na S.Casa 
The mandei uma carta que se eu ir responder ozuro quero ser condenada em vida, que pello meu crime que tenho come tido e tudo oresto que tenho feito, meresaria deser fuzilada, mas para eu sair daqui para ir com minha gente nem depois, de morta, nào quero ir nem como marido nem com os, parentes eu não posso, mais, com binar.

Eu estou arrependida, que preferiria que Deus me dese a morte antes de viver sempre appenalizada desta maneira, tem dia que choro muito tem outros que digo sejafeita a vontade de Deus, quero rezar muito para ir morer junto com meu anzinho la na gloria no céu,

Pacei toda a noite escrevend-o, tudo oque iscrevi aqui e todas verdade, com, verdade, que tem o sol e a lua,

La na santa casa uma veia me dise tu es-boba que tu estaes fazendo aqui vai na Rua, tu se justa, in qual que familhia tu ganha os 30,000 res, a justicia não vem tem pricurar, praque aqui é ullugar grande nào te assam, mais, eu the respondi, eu tenho cometido ogrime e presiso qu faza aminha, penitencia elhe dise que, eu nunca foi mulher de Rua, a frera, intendeu, A senhora não sabe oque lhe poderia acontece, que ella não sai, ma se saísse a curpa e sua.

Senhores, Dotores, eu lhe peço por favor, eu tenho dois lugares ou cadeia por toda vda ou aqui, mas não nas familhias, não, quero, ir não, desejo mais de passar nem um, dia de vida familha, pelos meus feios nomes, que tenho, porém pra sair da qui pra ir num lugar mas, triste não, saria contente, eu aqui za estou me acostumando, sou muito bem tratada, que não, mereço, eu, sou sãm e forte, naotenho, duensa, nem uma, eu tenho feito, algumas, bobajas, mas, sempre com o meu juízo firme, isto que, eu fazia, não fazia por minha vontade creio que era por vontade, do diabo, elle queria, to mar, a minha alma mas, até o dia de hoge, ainda elle não, puide me tomar, porque eu tenho Deus comigo.

Eu lhe in trego, estas cartas, Senhores pode lhemos trar ao chefe, de polisa, Agora o Senhores, podem fazer o que, intem der, eu nào mereço de me fazer bem, maz isto está em suas vontade, eu para sair daqui, ficaria, muito sentida porque, medou, muito, comas empregadas,

Acabo porque estou com sono penso que isto sega aqui está tudo esplicado.

\section{A criminoza Pierina Cechini}

Os senhores, intende que, eu não tenho coragem de dizer que estou, arrendida de medo de ser absol vida, mas estou mil vezes, e tambem teria muita vergonha de ir aresponder ou juro, mas se for, presizo, os senhores, me avisam, us 15 dias antes, agora não tenho nada no coração, OS, Senhores me descurpes pellos erros, porque foi escrita, de toda a noite,

A criminoza Pierina Cechini 


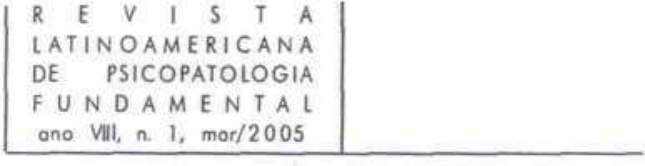

Senhores, Douttores, Eu, tinha mes esque sido do maz necessário esta noite, escreviou, resto, come ti este crime por amor, da minha filha, o povo, dizem, que uma mãe, que matta seus filho, tem, um coração de Tigre, mas, in veis, eu matei porter, um bom coração e por amor da minha filha, e para the dar um bom lugar no céu creio que ella esta gozando, felisidade, la na gloria, etão bem foi para me livrar de passar desgostos com o marido,

O meu marido, a vida delle era esta, se a sema, era todos dias de festa, elle era capaz, de passar a sema intera nas vendas, e quando vinha, a qual quer, horas da noite, bebedos, como um, porco, elle, lansava tudo, e assim, eu ficava, muito braba eralhava com elle, se lhe dizia semos tão pobre, e tu sempre bebedo a eta, maneira, Eu quando, era moça gostava de ir bem arumadinha e depois, me, vi que logo, tinha, de ir pedir esmola, a minha Etelvina era tão, bonita, que paresia um anzinho, eu de vella de ir mal arumada não gostava, e não tinha nada pra vestir ella, eu se não, come tia este crime, e se ficava junto como marido, e se Deus, me dava mais filhos eu tinha de ir com toda aminha trosa a pedir esmola, eu sou mais contente, de passar, ou resta, da minha vida, aqui, ou na cadeia antes, de ir, pedir, esmola, e depassar, o que tenho passado com o marido, eu lhe garanto que isto de pois da morte dos meus paes, isto tudo ma aconte, sia, por que, eu não, tenho, nem terra, nem casa nem nada, meus pães, tem um, quarta de terra velha, a 34 annos, que se trabalhava não da mais, nada, agora, depois, da morte, de meu pãe, meio quarto e aparte de minha, mãe, e outro meio, e pra repartir entre nois seis irmães. Os Senhor calcules, quanta sustansa, nos tinha,

Mas Deus e messericodioso, elle a deter missericordia, de mi, este tudo que passei na minha vida, e o quetenho, depassar, Eu gostaria que, estas cartas, foce, tudo, num jornal para tudo o povo, saber, maz, eu não, tenho dinheiro, para mandar no Coreio do povo,

Os Senhores Lhe dou li sensa de ler todas as carta, até; ou coverno se quiser, Mas lhe peço porfavor de ter um pouco, de piedade de mi, eu não, mereço, maz enfim, este, crime não foi como tido por gosto foi por vontade De Deus, e para necesidade, eu não tenho, duensa ne um grasasas as a Deus eu, poço trabalhar, dia enoite, eu tenho, uma boa, memoria que desda idade de simco annos, sei lhe contar aminha vida, etão, bem quando, vejo, fazer um trabalho, um veis sega, noutro dia ja sei fazer, Se os senhores me dese um inpreguinho aqui, no hospicio, de ganhar um 15 mereis, por méis, pra, mise garia, lhe peço pofavor, de ter, piedade de mi,

Pierina Cechini

Criminoza: apenalizada 